\title{
A method for pedestrian crossing risk assessment
}

\author{
D. Antov ${ }^{1,2}$, T. Rõivas ${ }^{3}$, I. Antso ${ }^{2,3} \&$ P. Sürje ${ }^{1}$ \\ ${ }^{1}$ Tallinn University of Technology, Estonia \\ ${ }^{2}$ Stratum Consultancy, Estonia \\ ${ }^{3}$ Tartu University, Estonia
}

\begin{abstract}
Pedestrian crossings are contributing to important risk sites, especially at urban traffic environments. For example, in Tallinn, the capital of Estonia during the period of 2006-2009, one of three injury accidents took place at non-signalized pedestrian crossings. But it is still complicated to rank crossings due to the number of registered road accidents, because of some main reasons, such as (i) It is doubtful to wait for accidents to happen in order to take measures for their removal, and; (ii) Often a statistical inadequacy causes problems for ranking, as the number of registered accidents is often too small for comprehensive analysis.

Thus, there is a big need for indirect risk ranking, in order to find the most reliable measures for safety improvement of pedestrian crossings. An additional problem occurs when the road accident took place close to a crossing, but not exactly at a crossing. Then the accident, even connected to the crossing site, might fall out of traditional statistics, thus registered under a different accident type.

The project initiated in Tallinn had two main goals:

Working out the method for road accidents mapping at the vicinity of a crossing.

Developing the indirect method for the potential risk estimation of pedestrian crossing, using the number of potential risk factors, including the design (e.g. roadway width and layout), behavioural (e.g. speed) and others.
\end{abstract}

Keywords: road safety, risk assessment, pedestrian crossings, road safety inspection. 


\section{Introduction}

Motorised road transport plays a central role in the most of societies. As the goods needed for everyday life are transported mainly by road and the population have great opportunities for motorised travel in the course of work and leisure than before. This advantage has been achieved, however, at some cost. High levels of motorization contribute to serious consequences such as human and economic costs measured in terms of the numbers of accidents people killed and injured in these accidents. The experience of many countries has shown that it is perfectly possible to introduce measures that greatly reduce these human and economic costs [1].

Road accidents and their consequences are a significant social problem. At the same time, this topic can be considered to be one of the indicators of the sustainable development of urban systems. More than 10,000 pedestrians and cyclists are killed every year in EU countries, representing more than 20 per cent of all road deaths. The small proportion of pedestrian and cyclist casualties that occur in rural areas are relatively severe and should not be forgotten, but this review is concerned with the majority, which occur in urban areas.

Pedestrian safety is also one of the most serious problems in traffic, especially in urban areas. If one compares Estonia's figures with those of the neighbouring country Finland, the pedestrian road traffic risk in Estonia is somehow 2-4 times higher. The situation is extremely alarming in urban areas, which account for approximately 85 per cent of all pedestrian accidents in Estonia. It is documented that every fourth urban pedestrian accident occurs at non-signalized pedestrian crossings, often referred to as zebra crossing, or in their vicinity $[2,3]$.

Improving roadway safety is an ongoing priority for transportation agencies. However, addressing safety issues in rural areas is difficult for local governments due to the limited resources available for maintenance and improvement projects.

Risk assessment during the road safety evaluations have emerged as an effective type of tool for identifying and addressing road safety issues. A number of countries have introduced standard and routine safety evaluation activities, such as road safety inspection and auditing. According to the U.S. Federal Highway Administration (FHWA), road safety audits noticeably improve the safety performance of roadway facilities. Several benefits can be achieved through the implementation of road safety audits, such as low-cost/high-value improvement opportunities, promoting the awareness of safe design and maintenance practices, and providing a means to tailor the resources of an agency to meet specific problems [7].

\section{Road accidents involving pedestrians}

The fatality risk of pedestrians, car passengers and drivers in the Baltic countries, including Estonia are much greater than in countries with good safety performances such as Finland (Figure 1). Especially some road accident types like vulnerable road users' (pedestrians and cyclists) accident and single vehicle 
accidents on rural roads are predominating in Estonia. There are different explanations on that. One is relatively low rates of passive safety equipment usage, such as seat belts or child restraints, which cause high severity of accident results in the case of crash occurrences. Secondly, it is also evident that the most disconcerting data describe the disparity in pedestrian fatalities. It can be seen in Figure 1 that the Estonian pedestrian data are three times higher than in Finland. Clearly pedestrian safety and more effective use of safety equipment need to be a key part of programs designed to lower fatality rates.

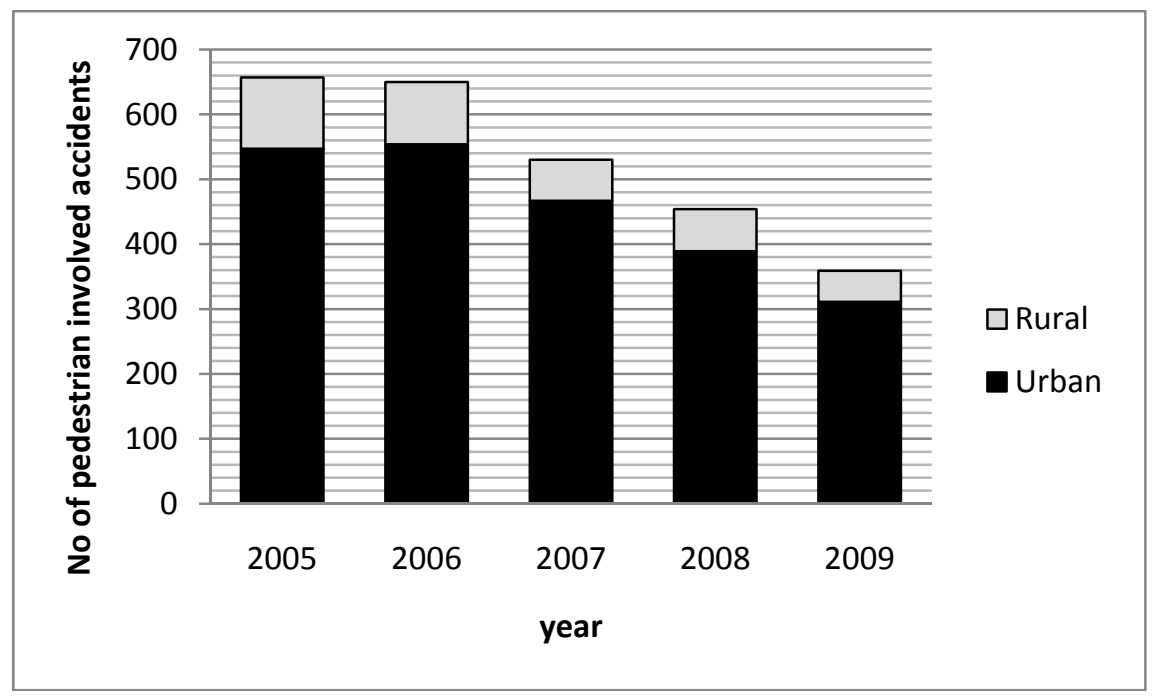

Figure 1: Road accidents involving pedestrians in rural and urban areas of Estonia.

Table 1: The share of road accident types (\%) in Estonia, Latvia and Finland [2].

\begin{tabular}{|l|l|l|l|}
\hline \multicolumn{1}{|c|}{ Road accident type } & Estonia & Latvia & Finland \\
\hline Single vehicle accident & 32.8 & 24.7 & 25.3 \\
\hline $\begin{array}{l}\text { Accident between motor } \\
\text { vehicles }\end{array}$ & 15.2 & 19.5 & 49.0 \\
\hline Accident with mopeds or cycles & 10.8 & 8.2 & \\
\hline Collision with obstacle & 1.0 & 6.9 & 12.4 \\
\hline Pedestrian accident & 38.7 & 39.7 & 13.3 \\
\hline Other types & 1.5 & 1.0 & \\
\hline Total & 100 & 100 & 100 \\
\hline
\end{tabular}




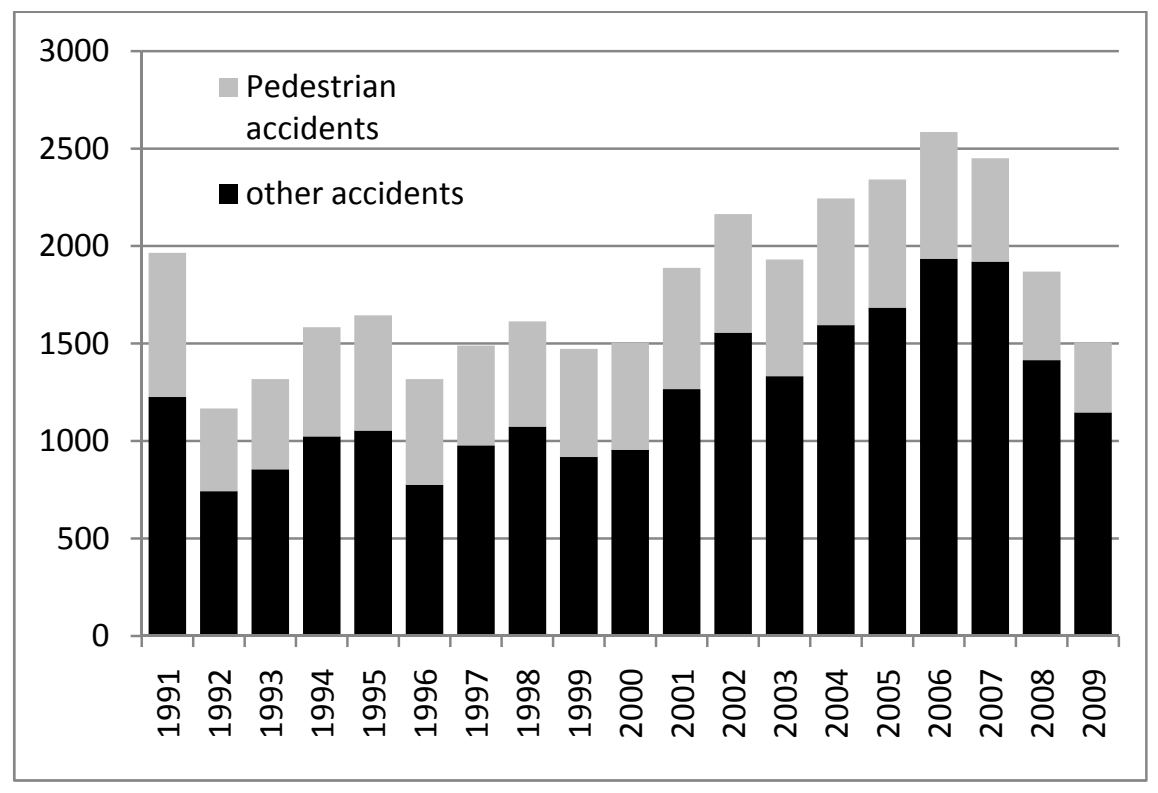

Figure 2: Development of road accidents and pedestrian accidents in Estonia 1991-2009.

Table 1 show that pedestrians account for a remarkably high proportion of all road fatalities. If one assumes the position that programs to address pedestrian fatalities are easier to implement than addressing strictly driver behaviour, then there is substantial potential to decrease road-related fatalities. These potential programmes are discussed in a subsequent section.

\section{Safety at crossings}

Junctions and crossings are places where many pedestrians need to cross the road despite the risks in doing so, and in Tallinn, for example, over 20 per cent of pedestrian crashes occur at non-signalised crossings. This ranks second in road elements after straight street sections, which includes the locations at the vicinity of crossings as well (Figure 3). Safe layout and sharing of the road space with the help of signs, markings and distinctive surfacing can simplify the tasks facing pedestrians and cyclists at junctions and thus reduce casualties.

Pedestrian crossings are perceived to be safe places to cross the road, although this is not necessarily the case. While crossings give some protection to the young and elderly, many crashes occur in their vicinity: the 50m either side of a crossing is particularly dangerous. Dropped kerbs at crossings assist those with physical impairments while tactile surfaces help those with visual impairments. Refuge islands or a continuous central reservation provide help in crossing. 
Table 2: $\quad$ Share of pedestrian accidents on urban and rural roads.

\begin{tabular}{|l|r|r|r|r|r|}
\hline Year: & 2005 & 2006 & 2007 & 2008 & 2009 \\
\hline $\begin{array}{l}\text { Accidents in total: } \\
\text { of which: }\end{array}$ & 2341 & 2585 & 2450 & 1869 & 1508 \\
\hline $\begin{array}{l}\text { Pedestrian accidents on } \\
\text { rural roads }\end{array}$ & 110 & 96 & 63 & 65 & 48 \\
\hline $\begin{array}{l}\text { Other accidents on rural } \\
\text { roads }\end{array}$ & 871 & 1046 & 1068 & 717 & 618 \\
\hline $\begin{array}{l}\text { Pedestrian accidents on } \\
\text { urban roads }\end{array}$ & 547 & 554 & 467 & 389 & 311 \\
\hline $\begin{array}{l}\text { Other accidents on } \\
\text { urban roads }\end{array}$ & 813 & 889 & 852 & 698 & 531 \\
\hline
\end{tabular}

Zebra crossings are also often used because of their relatively low cost. The choice of facility to provide will depend upon local circumstances. Speed plays an important role in determining the severity of the outcome of collisions. If the collision speed exceeds $45 \mathrm{~km} / \mathrm{h}$ the likelihood for a pedestrian or cyclist to survive the crash is less than 50 per cent. If the collision speed is less than $30 \mathrm{~km} / \mathrm{h}$ more than 90 per cent of those struck survive [10]. Speed management, therefore, is a key element in a safe traffic system for vulnerable road users.

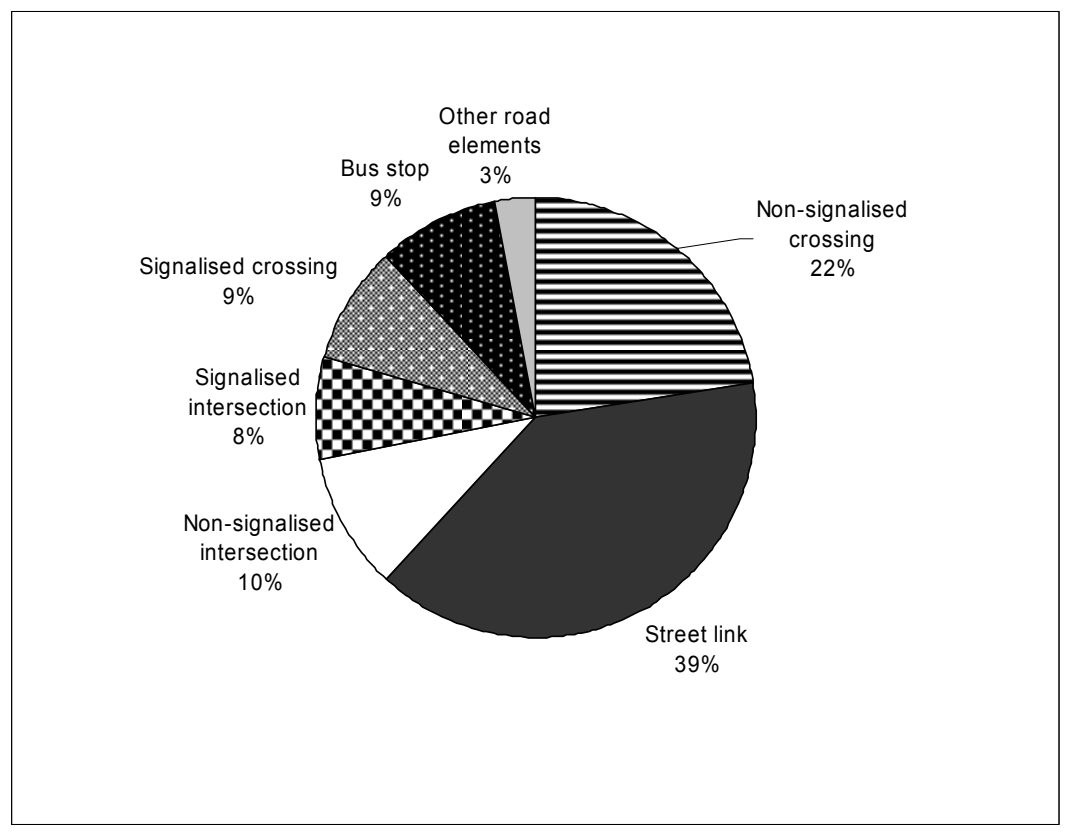

Figure 3: $\quad$ Location of pedestrian accidents in Tallinn, 2006-2009. 


\section{Road safety assessment needs}

In a number of cases there is a need for objective estimation of road safety risks on certain sites of the road, including pedestrian crossings. This may be a case for traditional safety assessment, conducted regularly by road authorities, or activities carried on during the road safety inspection, or any other purposes. The Basic methods used for this purpose are:

- Method based on road accident statistics

- Indirect safety assessment methods (e.g. traffic conflict survey)

- Subjective methods of risk assessment often based on experiences of the experts (which is often the case during road safety inspections)

- Method based on former surveys or experiences from the different countries (e.g. road safety handbook).

Scientific research has produced lots of good estimates on the effects of safety improving measures [10]. The effects are usually presented as a percentage change in the number of injury accidents. So it is vital to be able to evaluate reliably what would have happened if the road safety measure had not been implemented. Our experience suggests that the greatest mistakes in evaluating the safety effects of road improvements are done while evaluating the current safety situation.

According to the empirical Bayesian method, the best estimate of safety is obtained by combining two sources of information: the accident record for a given study unit (e.g. road section), and an accident prediction model, showing how various factors affect accident occurrence [8].

The safety evaluation of a given road is frequently based only on accidents happened during recent years. However, due to random variation and rareness of accidents, accident history provides an unreliable estimate of the expected number of accidents in the future. This is even truer regarding evaluation of fatalities. Consequently, if the current safety situation is inadequately evaluated, one cans nothing but fail in evaluating the effects of road safety improvements. Similar problems concern so-called black spots with relatively small number of accidents during few last years.

The main goal of this project is to develop a methodology for identifying and conducting traffic safety evaluations at pedestrian non-signalized crossings in Estonia. This method of risk assessment evaluates the elements of a roadway facility which present a safety concern in the context of the extent of the safety concern, the road users who are affected, and the circumstances which pose the greatest safety issue. Based on these concerns, risk assessment methods look to provide opportunities to eliminate or mitigate the identified safety concerns. It should be noted that method for risk assessment is not a mean to evaluate design work, compliance with standards, or a tool to rank various projects/designs. 


\section{Benefits}

There are quantitative and qualitative benefits to conducting risk assessment. Several of the qualitative benefits are defined by the U.S. FHWA as follows [5]:

- Takes a pro-active approach to addressing safety

- Results should produce fewer and less severe crashes

- Allows for the identification of low-cost/high-value improvements

- Promotes a safety-conscious environment by improving the consistency of how safety is considered

- Provides a continuous advancement of safety knowledge

- Provides a benchmark for safety issues on future projects

- Promotes an efficient use of time, money, and resources.

The quantifiable benefits of conducting a risk assessment are primarily based on the reduction of crash costs as road safety is improved [6]. However, several other quantifiable benefits have been documented, such as:

1) The elimination of re-construction costs to correct safety deficiencies in roadway facilities (pre-construction evaluation);

2) The reduction in lifecycle costs due to the lower maintenance costs of safer designs;

3) The reduction of societal costs due to collisions;

4) The reduction of liability costs due to safer roadway facilities [9]. It should be noted that the achievement of a target cost/benefit ratio is generally not the motivation for support of risk assessment.

\section{Safety effect evaluation practices}

Road improvements or especially black spot treatments aim at reducing future accidents on the network where accident cost reduction potential is highest [12]. Rosebud project studied the effectiveness of road projects and stated: "The quantification of the effects of measures aimed at reducing crashes represents a critical point for the application of Cost Benefit Analysis and Cost Effectiveness Analysis techniques to road safety. The major source of knowledge on safety effects are evaluation studies of past treatments. The most common form of a safety effect is the percentage reduction of crashes following the treatment (sometimes called the "crash reduction factor") [13].

Method based on injury severity density has been developed in Norway to identify hazardous road sections [4]. This concept could be used also for the estimation of current safety situation. 
At the beginning of the 1990s the Finnish Road Administration and Technical Research Centre (VTT) concluded that the estimation of avoided accident due to road improvements should be done in two phases $[11,14]$ :

1. Estimation of the current safety situation on an existing road, combining information from simple accident models and accident history

2. The safety effect of road improvements can be estimated using the current safety situation and safety impact coefficients (or crash reduction factors) based on most reliable research results available around the world.

\section{Method for risk assessment at pedestrian crossing}

Estonian situation is similar to the Finnish, described above. Very often the problems are related to relatively small number of registered accidents, which causes problems with statistically based assessment reliability. And the second problem is that the situation at the single crossing will most probably change over the time of statistical information has been carried, thus the minor or even major changes will have their influence on safety performance.

In a review of practical evaluations we found out that even more important than the reduction factors is the estimation of current traffic safety situation. Evaluation error in current safety situation can be even bigger than the true expected number of accidents, if the random variation of accidents is not taken into account appropriately.

This method is basically based on evaluation of a number of single factors which are relevant to a number of crossings. Every single factor is getting a risk coefficient and then combining the factors the one can calculate a total risk coefficient. Risk coefficients used for the method, are based on local and internationally recognized survey results, as well as on local subjective assessment, introduced during the risk assessment practices, like road safety inspections.

As it is relevant that risk coefficients are still rather subjective, we are linking the summarized risk to risk group, thus the minor inadequacy could be eliminated.

Risk coefficients are already shared between five main types of risk assessment. The first and the most important is crossing design (or shape), followed by additional risk factors and introduced safety measures. These factors are listed below. But also some additional objective characteristics are going to be introduced as well, containing of speed behavioural factors $(85 \%$ speed if available) and the number of registered casualty accidents. 


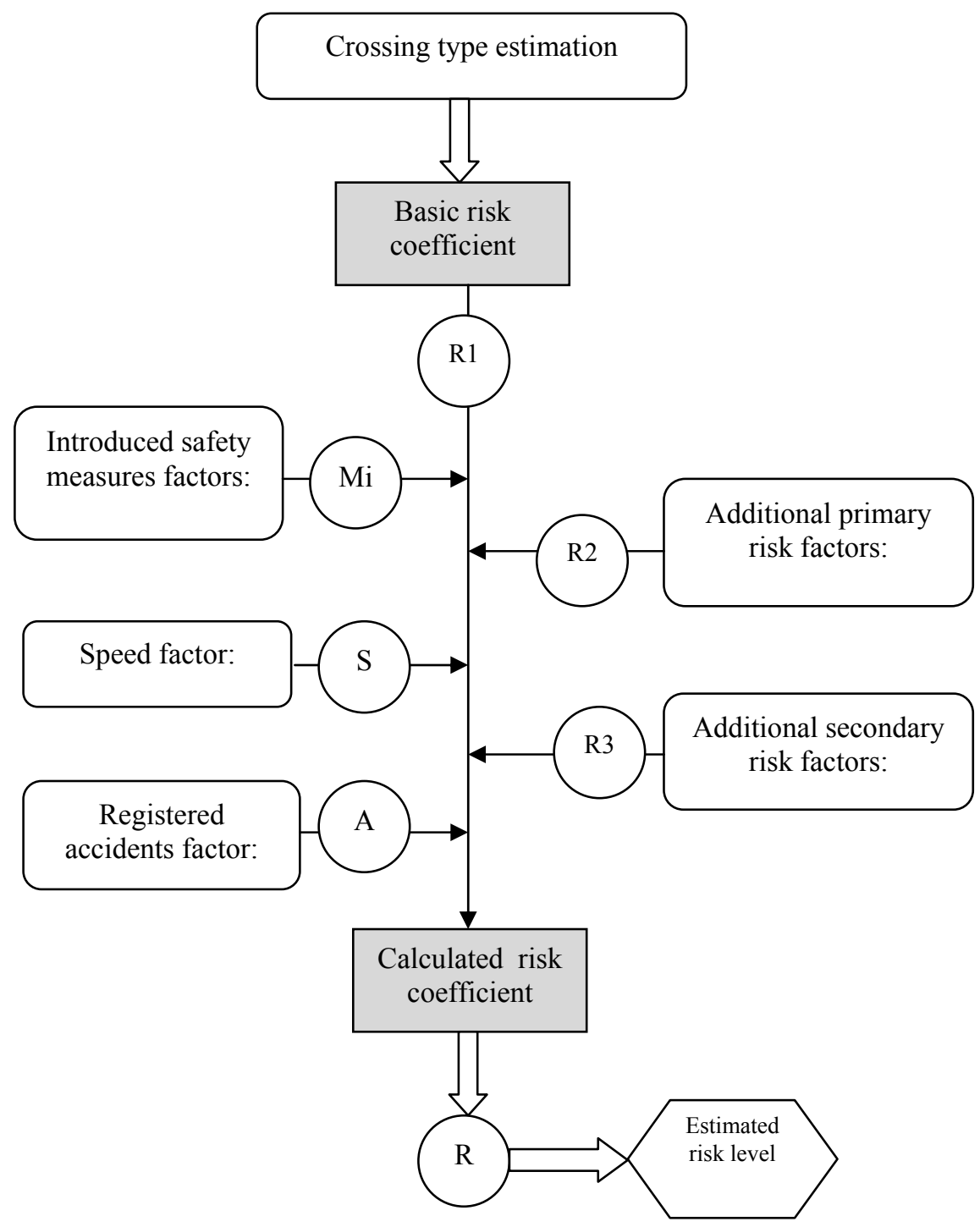

Figure 4: Pedestrian crossing risk estimation flowchart. 
Table 3: List of potential risk factors included for pedestrian crossing risk assessment.

\begin{tabular}{|c|l|}
\hline Type A & Pedestrian crossing at access road \\
\hline & $\begin{array}{l}\text { Pedestrian crossing at: } \\
\text { - one-directional road }\end{array}$ \\
Type B & - two-directional road with refugee (width over $1.5 \mathrm{~m}$ ) island or area \\
\hline & $\begin{array}{l}\text { Pedestrian crossing at: } \\
\text { two-directional road without refugee island or area }\end{array}$ \\
Type C & I : Additional primary factors: \\
\hline 1 & Roadway width \\
\cline { 2 - 3 } 2 & Number of driving lanes \\
\hline
\end{tabular}

\section{II : Additional secondary risk factors:}

\begin{tabular}{|c|c|}
\hline 1 & Road edge with curb \\
\hline 2 & Lighting \\
\hline 3 & Alignment of crossing \\
\hline 4 & Children facilities located in the neighbourhood \\
\hline 5 & Crossing covers bus stop pocket or turning lane \\
\hline 6 & Street signing quality \\
\hline 7 & Limited visibility (e.g. parking) \\
\hline 8 & Pedestrians cross the road nearby \\
\hline 9 & Traffic signs location and visibility \\
\hline
\end{tabular}

III : Safety measures introduced

10 Raised crossing or chicane

11 Road humps

12 Coloured crossing

13 Built safety island

14 Temporary safety island, introduced traffic sign

15 Roadway narrowing at crossing

16 Local crossing lighting introduced

17 Precaution traffic sign or reflecting background of traffic sign used

18 Pedestrian guardrail

19 Other safety measures introduced

\section{IV : Real speed (v85)}

\section{$\mathrm{V}:$ Registered road accidents (injured or killed)}

No of road accidents during the last 36 months 


\section{Acknowledgements}

This research was supported by the European Social Fund's Doctoral Studies and the Internationalisation Programme DoRa.

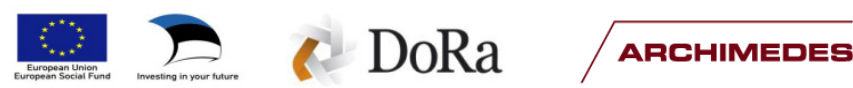

\section{References}

[1] Raising Compliance with Road Safety Law. 1st Road Safety PIN Report. Written by F.Achtenberg. ETSC, 2007.

[2] I.Pihlak, D.Antov. Unterschiede in der Strassenverkehrssicherheit Zwischen den Baltischen Staaten und Finnland. Strassenverkehrstechnik, 8/2002. pp. $394-400,2002$.

[3] D.Antov, S.Sööt. Toward Improved Traffic Safety: Road Use Perception and Behavior in Estonia. Journal of the Transportation Research Board. Transportation Research Record No 1818, Washington, D.C. pp. 1-6, 2002.

[4] Ragnøy, A., P. Christensen, R. Elvik. Skadegradstetthet. Et nytt mål på hvor farlig en vegstrekning er. Rapport 618. Transport-økonomisk institutt, 2002.

[5] Road Safety Audits (RSA). Federal Highway Administration. http://safety.fhwa.dot.gov/rsa/

[6] Gibbs, Margaret et al. Road Safety Audits: Case Studies. Opus Hamilton Consultants Ltd, Vanasse Hangen Brustlin Inc, Federal Highway Administration. December, 2006.

[7] Baker J., Johnson, K., Vachal, K. Implementing Traffic Safety Evaluations to Enhance Roadway Safety Upper Great Plains Transportation Institute North Dakota State University, Fargo, 2010.

[8] Elvik, R. Quantified road safety targets: A useful tool for policy making? Accident Analysis \& Prevention, Volume 25, pp.569-583, 1993.

[9] McGill, J. et al. Road Safety Audit Guidelines. Science Applications International Corporation, Synectics Transportation Consultants, Kittelson and Associates, CTRE, Penn State, Federal Highway Administration. Washington, D.C. February, 2005.

[10] Elvik, R. \& Vaa, T. The handbook of road safety measures. Oxford: Elsevier Science, 2004.

[11] Peltola, H. Accident models. NVF conference in Iceland September 7.8. 2006.Theme Accident data. Online. http://ptl.fi/NVFnorden/priv/vf52/ seminarer.htm

[12] Francesconi, S. Road Infrastructure Safety - jointly reaching Europe's target. Online: http://www.ripcordiserest.com/ 
[13] Rosebud. Road safety and environmental benefit-cost and costeffectiveness analysis for use in decision-making thematic network. Deliverable 7 WP5-Recommendations. Online: http://partnet.vtt.fi/rosebud/

[14] Peltola, Harri. Evaluating measures in order to achieve safety targets. VTT, Technical Research Centre of Finland, 2006. 